\title{
THE USE OF ENHANCED NOZZLE MAPS FOR GAS-TURBINE PERFORMANCE MODELLING
}

\author{
Aws A. Al-Akam \\ Formerly at Centre for \\ Propulsion Engineering, \\ Cranfield University. \\ University of Babylon, \\ Faculty of Engineering- \\ Musayib \\ Babil, Iraq
}

\author{
Theoklis Nikolaidis \\ Centre for Propulsion \\ Engineering, Cranfield \\ University \\ Cranfield, Bedford, \\ Bedfordshire, England, \\ UK
}

\author{
David G. MacManus \\ Centre for Propulsion \\ Engineering, Cranfield \\ University \\ Cranfield, Bedford, \\ Bedfordshire, England, \\ UK
}

\author{
Alvise Pellegrini \\ Centre for Propulsion \\ Engineering, Cranfield \\ University \\ Cranfield, Bedford, \\ Bedfordshire, England, \\ UK
}

\begin{tabular}{|c|c|c|}
\hline \multicolumn{3}{|l|}{ ABSTRACT } \\
\hline The use of a simulation tool to predict the aero-engine & \multicolumn{2}{|c|}{ NOMENCLATURE } \\
\hline performance before committing to a final engine design has & $\mathrm{A}_{\mathrm{bp}}$ & Bypass nozzle area, $\left[\mathrm{m}^{2}\right]$ \\
\hline become one of the most cost-saving approaches in this field. & $\mathrm{A}_{\text {core }}$ & Core nozzle area, $\left[\mathrm{m}^{2}\right]$ \\
\hline However, most of these tools are based on low fidelity & $A_{e}$ & Nozzle exit area $\left[\mathrm{m}^{2}\right]$ \\
\hline thermodynamic models, which are incapable of fully capturing & $\mathrm{A}_{\text {in }}$ & Nozzle inlet area $\left[\mathrm{m}^{2}\right]$ \\
\hline the impact of three-dimensional flow characteristics. & $\mathrm{A}_{\mathrm{th}}$ & Throat Area, $\left[\mathrm{m}^{2}\right]$ \\
\hline An aero-engine exhaust-system is one of the essential & $\mathrm{AR}$ & Area ratio, $[-]$ \\
\hline components that affect the engine performance. Currently, & CFD & Computational Fluid Dynamics \\
\hline engine performance models tend to utilize simplified nozzle & $\mathrm{CR}$ & Bypass nozzle Contraction ratio \\
\hline performance maps. These maps typically provide information & $\mathrm{cCR}$ & Core nozzle Contraction ratio \\
\hline over a very limited range of nozzle geometries, which may not & $\mathrm{CS}$ & Cubic-spline \\
\hline apply to the wide range of architectures and designs of aero- & $\mathrm{C}_{\mathrm{v}}$ & Velocity coefficient [-] \\
\hline engines. & $\mathrm{C}_{\mathrm{fg}}$ & Gross thrust coefficient $[-]$ \\
\hline The current paper presents a methodology for the & $\mathrm{F}_{\mathrm{g}}$ & Gross thrust, $[\mathrm{N}]$ for the performance model \\
\hline development of nozzle performance maps, which takes into & $F_{G}$ & Gross thrust, $[\mathrm{N}]$ for the CFD model \\
\hline account the aerodynamic and the geometric parameters of the & $\mathrm{m}$. & Mass Flow rate, $[\mathrm{kg} / \mathrm{s}]$ \\
\hline nozzle design. The methodology is based on the reduced-order & $m_{\text {i noz. }}$ & Ideal Mass Flow rate of the nozzle, $[\mathrm{kg} / \mathrm{s}]$ \\
\hline models. These models are integrated into a zero-dimensional & $\mathrm{M}_{\mathrm{in}}$ & Fan Exit Mach number [-] \\
\hline engine performance code to improve the accuracy of its thrust & $\mathrm{M}_{\infty}$ & Free stream Mach number [-] \\
\hline calculation. & MFCR & Mass flow capture ratio [-] \\
\hline The impact of the new thrust model on the overall engine & $\mathrm{N}$ & Rotational Speed \\
\hline performance and the operating point is analysed and discussed. & NPR & Nozzle pressure ratio \\
\hline The results showed that the implementation of the modified & $\mathrm{NPF}$ & Net Propulsive force, $[\mathrm{N}]$ \\
\hline maps, which take into account the flow characteristics and the & FNPR & Fan nozzle pressure \\
\hline geometry of the nozzle, affects the thrust calculation. In a typical & CNPR & Core nozzle pressure ratio \\
\hline case of a turbofan operating at cruise conditions, the net thrust & PR & Pressure ratio $[-]$ \\
\hline estimation with the modified nozzle maps showed a difference of & $\mathrm{Pt}_{\text {in }}$ & Total pressure at the nozzle inlet, $[\mathrm{K}]$ \\
\hline $0.2 \%$, compared with the simple nozzle maps. The new thrust & $\mathrm{Tt}_{\mathrm{in}}$ & Total temperature at the nozzle inlet, $[\mathrm{K}]$ \\
\hline calculation method has the advantage in capturing the & TR & Ratio of the total temperature \\
\hline multidimensional impact of the flow of the nozzle as compared & TET & Turbine Entry Temperature, $[\mathrm{K}]$ \\
\hline with the conventional one. Furthermore, the implementation of & $\beta_{\mathrm{cc}}$ & Core cowl angle, $\left[{ }^{\circ}\right]$ \\
\hline the new method reduces the uncertainties introduced by a & $\beta_{\mathrm{pl}}$ & Plug angle, $\left[{ }^{\circ}\right]$ \\
\hline simplified nozzle model and, consequently, it can support the & $\mathrm{V}_{\mathrm{e}}$ & Exit velocity, $[\mathrm{m} / \mathrm{s}]$ \\
\hline decision-making process in the design of the engine. & $\mathrm{V}_{\mathrm{s}}$ & Isentropic velocity, $[\mathrm{m} / \mathrm{s}]$ \\
\hline Keywords: aero-engine, nozzle maps, engine performance, & $\mathrm{p}_{\mathrm{e}}$ & Exit static pressure, $[\mathrm{pa}]$ \\
\hline nozzle modelling. & $\mathrm{p}_{\infty}$ & free -stream static pressure, $[\mathrm{pa}]$ \\
\hline & RSM & Response surface method \\
\hline
\end{tabular}
performance become one of the most cost-saving approaches in this field. the impact of three-dimensional flow characteristics.

An aero-engine exhaust-system is one of the esse engine performance models tend to utilize simplified nozzle performance maps. These maps typically provide information gines.

The current paper presents a methodology for the nozzle design. The methodology is based on the reduced-order models. These models are integrated into a zero-dimensional engine performance code to improve the accuracy of its thrust The maps, which take into account the flow characteristics and the maps showed a difference of $0.2 \%$, compared with the simple nozzle maps. The new thrust the new method reduces simplified nozzle model and, consequently, it can support the

Keywords: aero-engine, nozzle maps, engine performance, $\mathrm{p}_{\infty}$
Bypass nozzle area, $\left[\mathrm{m}^{2}\right]$

Nozzle exit area $\left[\mathrm{m}^{2}\right]$

Nozzle inlet area $\left[\mathrm{m}^{2}\right]$

a ratio, $[-]$

Bypass nozzle Contraction ratio

Core nozzle Contraction ratio

Velocity coefficient [-]

Gross thrust coefficient [-

Gross thrust, $[\mathrm{N}]$ for the CFD model

Mass Flow rate, $[\mathrm{kg} / \mathrm{s}$

Fan Exit Mach number [-]

Free stream Mach number [-

ow capture ratio [-

Nozzle pressure ratio

$[\mathrm{N}]$

Core nozzle pressure ratio

Total temperature at the nozzle inlet, $[\mathrm{K}]$

Core cowl angle, $\left[{ }^{\circ}\right.$

Plug angle, $\left[{ }^{\circ}\right]$

Isentropic velocity, $[\mathrm{m} / \mathrm{s}]$

free -stream static pressure, [pa]

Response surface method
Throat Area, $\left[\mathrm{m}^{2}\right]$ 


\section{SFC}

Specific Fuel consumption, [mg/Ns]

\section{SUBSCRIPTIONS}

$\begin{array}{ll}1,2 & \text { Refers to the first and second selected } \\ \text { value of } \beta & \text { Refers to the first and second selected } \\ \text { value of CR } & \text { After-body } \\ \text { ab } & \text { Bypass } \\ \text { bp } & \text { Core cowl } \\ \text { cc } & \text { exit } \\ \text { e } & \text { gross } \\ \text { g } & \text { Refers to the first and second selected } \\ \text { X,y } & \text { value of NPR } \\ \text { in } & \text { inlet } \\ \text { i } & \text { ideal } \\ \text { noz } & \text { nozzle } \\ \text { pl } & \text { plug } \\ \text { s } & \text { isentropic } \\ \text { t } & \text { Total } \\ \text { th } & \text { Throat } \\ \text { v } & \text { velocity } \\ \infty & \text { Free-stream }\end{array}$

\section{INTRODUCTION}

Nowadays, the economic considerations, which accompany the aircraft design and manufacturing process, are quite critical. Implementing new technology into this process evolves an economic risk, which should be minimized before the full manufacturing process commences. For this, simulation is implemented to help the engineers on decision-making. Therefore, a considerable number of simulation tools were developed to provide a reasonably accurate prediction of the performance of the aircraft-engine system. Gas turbine performance can be evaluated by using different predictive tools, such as Turbomatch[1] and GasTurb [2], etc. Many of these tools are based on zero-dimensional isentropic thermodynamic equations. However, the multi-dimensional behaviour of the flow, inside or outside the engine, has a great impact on the predicted engine performance. In the case of aircraft-engine integration, the aerodynamic interaction between the engine components and the nacelle with the wing has a significant effect on the performance. Therefore, it becomes crucial to use a highfidelity model to predict the exterior and interior flow interactions of the aero-engine precisely. Mund et al., [3], by using computational fluid dynamics model (CFD), developed a two-dimensional representation of the intake, bypass duct and nozzle and consequently, the losses in these components were estimated. The results were employed to correct a zerodimensional performance model (Turbomatch) [1]. Mund et al. highlighted the importance of including the effect of the twodimensional interaction of the flow, during the engine performance simulation. Meanwhile, the engine installation effect on the performance of the aircraft and engine was examined by Sibilli [4], who combined the engine and aircraft performance model by taking into consideration the engine installation within the range of nacelle positions. This method is based on generating engine performance correlations to evaluate the installation impact. The correlations are represented by the ratio of the net propulsive force (NPF) (the net force of the engine transfer to the airframe) to the engine net thrust as a function of the engine position for two different types of engine. The change in the fuel consumed based on the variation in the axial position of the engine was estimated to be $4.2 \%$ [4].

The nacelle shape, free-stream Reynold's number (Re), freestream Mach number $\left(\mathrm{M}_{\infty}\right)$ and mass flow capture ratio (MFCR) effects were quantified by Christie et al, [5] who also corrected the isolated engine and the aircraft performance by assessing the impact of the up-flow angle. All these effects have been modelled using the empirical models from ESDU combined with a CFD approach. These models were integrated into an aircraft performance tool (Hermes) [6] developed at Cranfield University. The results showed that there was an increase in the amount of fuel burnt and reduction in the flight range throughout the flight trajectory because of the effect of the installation and the impact of the flow around the nacelle. The results also showed the importance of modelling the installation interference between the wing and the engine Christie et al., [5].

None of these studies has taken into account the impact of the geometrical and the operational parameters of the exhaust system on the overall engine performance. In this work, maps capture the geometrical impact alongside with the operational conditions on the engine performance was used. These maps were implemented in an appropriate engine performance simulation tool (Turbomatch) to assess their effects on engine overall performance.

\section{METHODOLOGY}

\subsection{Nozzle performance maps selection}

There are several nozzle performance map types available $[7,8]$. The main difference between them is the way the performance metric was calculated. Currently used maps are for a single-stream nozzle. Velocity coefficient $\mathrm{Cv}$ is the essential performance characteristic these maps provide based on the nozzle pressure ratio and area ratio (for supersonic nozzle).

The majority of the current fleet of civil aero-engines has a dual-stream nozzle. Therefore, it is required to use two sets of maps (one for each stream). Nozzle gross thrust coefficient maps were used for the by-pass and the core-nozzle. These maps were produced using a simplified nozzle configuration for different operational and geometrical parameters using computational fluid dynamics (CFD) method [9].

The main geometrical parameters are the core-cowl angle $\left(\beta_{\mathrm{cc}}\right)$, the plug angle $\left(\beta_{\mathrm{pl}}\right)$ and the contraction ratio $(\mathrm{CR})$ (the ratio of the inlet area $\left(\mathrm{A}_{\mathrm{in}}\right)$ of the nozzle to the exit area $\left.\left(\mathrm{A}_{\mathrm{th}}\right)\right)$ for the bypass nozzle, and cCR for the core nozzle, Fig 2. Moreover, the operational parameters i.e., the fan nozzle pressure ratio (FNPR) and the core nozzle pressure ratio (CNPR) were considered. The geometrical parameter range of the maps is the same for both 
nozzles, while the operational parameters are different. For the current work, cruise flight condition was chosen and consequently, FNPR was selected to be from 1.4 to 3.0. However, the core nozzle can operate in a wider range of PR than the fan nozzle. Consequently, CNPR ranges from $1.2-3.0$. The baseline nozzle configuration was sized based on engine performance simulation results, in terms of the nozzles' area and mass flow rate [9], Fig 1.

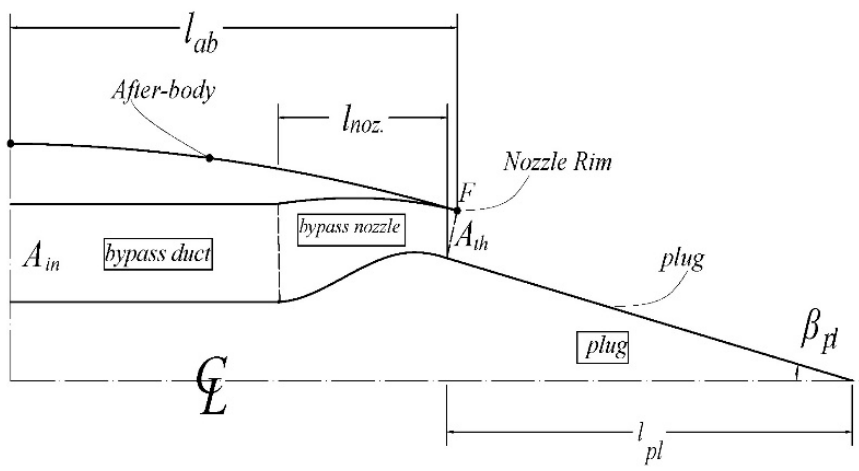

Figure 1. Section view of the nozzle configuration with the main geometrical lead parameters.

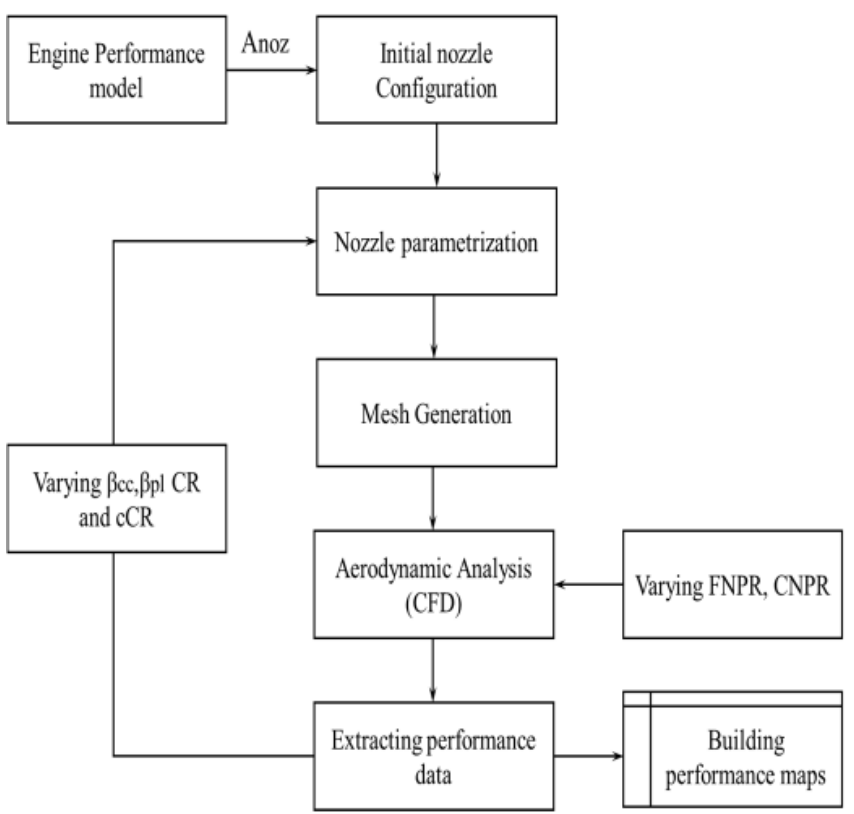

Figure 2: Nozzle maps generation method.

\subsection{Maps generation}

\subsubsection{By-pass nozzle}

For the representation of the bypass nozzle, a simplified nozzle configuration has been used with no consideration of the corenozzle impact on it, Fig 2. The initial geometry was produced based on the engine performance data derived from the simulation model in Turbomatch. The engine model was inspired by the architecture and performance of an engine similar to GE90. The performance calculations were performed at midcruise operating conditions (Alt. $=36,000 \mathrm{ft}, \mathrm{M}_{\infty}=0.82$ ), and a net thrust rating of $50.24 \mathrm{kN}$. The total-temperature ratio of the nozzle inlet was kept constant at $\left(\mathrm{T}_{\mathrm{t}} / \mathrm{T}_{\infty}=1.33\right)$ for all the range of NPR. Geometrical and operational parameters that have been covered in current CFD calculations are presented in Table 1. The core-cowl angle $\left(\beta_{\mathrm{cc}}\right)$, nozzle contraction ratio $\left(\mathrm{CR}=\mathrm{A}_{\mathrm{in}} / \mathrm{A}_{\mathrm{th}}\right)$ and nozzle pressure ratio (NPR) were changed. For each configuration, the effect of nozzle pressure ratio (NPR) was evaluated across the range from 1.4 to 3.0. The FNPR was varied by changing the inlet total-pressure of the nozzle.

Table 1. Parameterization cases simple nozzle (BP).

\begin{tabular}{|c|c|c|c|c|}
\hline \# & CR & $\beta c c$ & FNPR [-] & $M_{\infty}[-]$ \\
\hline 1 & 1.30 & $10^{\circ}-20^{\circ}$ (step $\left.1.0^{\circ}\right)$ & 1.4-3.0 (step 0.10) & 0.82 \\
\hline 2 & 1.40 & $10^{\circ}-20^{\circ}$ (step $\left.1.0^{\circ}\right)$ & 1.4-3.0(step 0.10) & 0.82 \\
\hline 3 & 1.53 & $10^{\circ}-20^{\circ}$ (step $\left.1.0^{\circ}\right)$ & 1.4-3.0(step 0.10) & 0.82 \\
\hline 4 & 1.60 & $10^{\circ}-20^{\circ}$ (step $\left.1.0^{\circ}\right)$ & 1.4-3.0(step 0.10) & 0.82 \\
\hline 5 & 1.67 & $10^{\circ}-20^{\circ}$ (step $\left.1.0^{\circ}\right)$ & 1.4-3.0(step 0.10) & 0.82 \\
\hline 6 & 1.74 & $10^{\circ}-20^{\circ}$ (step $\left.1.0^{\circ}\right)$ & 1.4-3.0(step 0.10) & 0.82 \\
\hline
\end{tabular}

\subsubsection{Core nozzle geometry}

To model the core nozzle, a dual-stream nozzle configuration was utilized, as the impact of the bypass nozzle flow should be included. The initial model design was based on the performance data that has been extracted from an engine performance model inspired by the high bypass ratio GE90 engine class. The performance calculations were performed at mid-cruise operating conditions (Alt. $=36000 \mathrm{ft}, \mathrm{M}_{\infty}=0.82$ ), and a thrust rating of $68.24 \mathrm{kN}$, (Fig 3). The impact of the fan nozzle pressure ratio (FNPR) on the performance of the core nozzle of a dualstream nozzle configuration was assessed. Therefore, FNPR was varied across the range of 1.0,2.0, 2.2 and 2.4. Besides that, the plug half-angle for this configuration $\left(\beta_{\mathrm{pl}}\right)$ was varied from $10^{\circ}$ to $20^{\circ}$ with a step of $1.0^{\circ}$, (Table 2). All the dual-stream nozzle simulations were carried out at $\mathrm{M}_{\infty}$ of 0.82 . The output performance data of the core nozzle will differ from the BP nozzle. The reason behind that is the flow-field of the core nozzle includes the stream tube of the bypass nozzle rather than the external flow. The external flow affects the BP nozzle flow and as a consequence the core nozzle. Therefore, it was suggested to produce correction factors to the core nozzle thrust data. These corrections relate the thrust coefficient of the core nozzle at a specific pressure ratio of the fan nozzle (FNPR) and the corenozzle performance data with FNPR 1.0. As a result, the corrections will assess the impact of the flow interaction between the bypass and the core nozzle.

Table 2. CFD geometrical and operational parameters of the dual-stream nozzle. 


\begin{tabular}{|c|c|c|c|c|c|}
\hline \# & FNPR & cCR & $\beta_{\mathrm{pl}}$ & CNPR[-] & $\mathbf{M}_{\infty}[-]$ \\
\hline 1 & 1.0 & $\begin{array}{l}1.35,1.43, \\
1.5,1.57 \\
1.67,1.77\end{array}$ & $10^{\circ}-20^{\circ}\left(\operatorname{step} 1.0^{\circ}\right)$ & $1.2-3.0($ step 0.10$)$ & 0.82 \\
\hline 2 & 2.0 & $\begin{array}{l}1.35,1.43, \\
1.5, \quad 1.57 \\
1.67,1.77\end{array}$ & $10^{\circ}-20^{\circ}\left(\operatorname{step} 1.0^{\circ}\right)$ & $1.2-3.0$ (step 0.10) & 0.82 \\
\hline 3 & 2.2 & $\begin{array}{l}1.35,1.43, \\
1.5, \quad 1.57, \\
1.67,1.77\end{array}$ & $10^{\circ}-20^{\circ}\left(\operatorname{step} 1.0^{\circ}\right)$ & $1.2-3.0$ (step 0.10) & 0.82 \\
\hline 4 & 2.4 & $\begin{array}{l}1.35,1.43, \\
1.5, \quad 1.57, \\
1.67,1.77\end{array}$ & $10^{\circ}-20^{\circ}\left(\operatorname{step} 1.0^{\circ}\right)$ & $1.2-3.0($ step 0.10$)$ & 0.82 \\
\hline
\end{tabular}

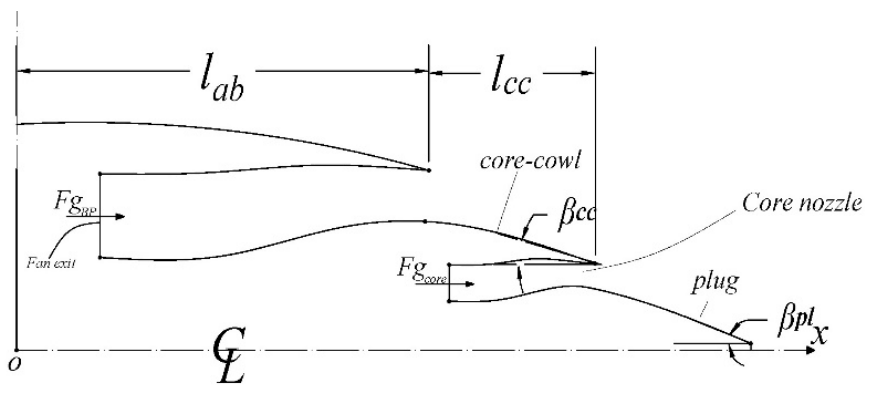

Figure 3. Schematic of the dual-stream nozzle configuration with the geometrical lead parameters.

\subsubsection{CFD modelling}

A two-dimensional axisymmetric CFD model was employed for the current analysis. The Numerical scheme was based on using Favre-Averaged Navier-Stokes (FANS) numerical methodology coupled with the k- $\omega$ Shear-Stress Transport (SST) turbulence model was employed. The simulations were conducted using a steady-state, implicit and density-based solver. The Green-Gauss node-based method was used to compute the flow field gradients. A second-order accurate upwind scheme was employed for the spatial discretization of the flow field. Sutherland's law was utilized for the calculations of dynamic viscosity [10], kinetic theory for the thermal conductivity and temperature-based polynomial correlation to estimate the specific heat [10]. Several cases were run after implementing the grid and domain sensitivity study [9]. The extracted data in terms of the pressure forces, drag and friction forces were used to calculate the nozzle gross thrust, in addition to the nozzle fluxes [9].

\subsection{Modified nozzle maps}

For the BP nozzle geometry, the development of the maps is based on the gross thrust coefficient $\left(\mathrm{C}_{\mathrm{fg}}\right)$ (Equation 1) [11] that was extracted from CFD calculations. $\mathrm{C}_{\mathrm{fg}}$ is represented by the ratio of the actual gross thrust that is extracted from the aerodynamic analysis (Equation 2), Where $F_{g(n o z)}$ represents the momentum flux and the pressure thrust at the charging plane of the nozzle. The ideal thrust calculated in equation (3-5). The extracted maps include different CR's as a function of the NPR and $\left(\beta_{\mathrm{cc}}\right)$, for the mid-cruise condition (Alt $=36000 \mathrm{ft}$ and $\left.\mathrm{M}_{\infty}=0.82\right)$, Fig 4 .
The derived value of the gross thrust coefficient $\left(\mathrm{C}_{\mathrm{fg}}\right)$ includes the impact of the geometry variation on the pressure-thrust term. The reason is that the pressure-thrust term $\left(\left(\boldsymbol{p}_{\boldsymbol{e}}-\boldsymbol{p}_{\infty}\right) \boldsymbol{A}_{\boldsymbol{e}}\right)$, (Equation 2) is represented by the integrated value of the pressure and the friction forces on the exhaust-system component. Moreover, the derived value of $\mathrm{C}_{\mathrm{fg}}$ encompasses the variation in the discharge coefficient, the internal losses of the nozzle in addition to the imperfect expansion of the nozzle.

$C_{f g}=\frac{\left(F_{G}\right)}{F i}$

$$
\left(F_{G}\right)=F_{g(n o z)}-\left(\int_{p l}\left(p-p_{\infty}\right) d \vec{A}+\int_{p l} \tau d \vec{A}\right)
$$

$$
\begin{aligned}
& F i=m_{i} V_{s} \\
& V_{s}=\sqrt{\frac{2 \gamma \mathrm{RT}}{(\gamma-1)}\left(1-\left(\frac{1}{\mathrm{NPR}}\right)^{\frac{\gamma-1}{\gamma}}\right)} \\
& m_{i}= \\
& \left.P_{0} A_{i}\left(\frac{1}{N P R}\right)_{c r i t}\right)^{1 / \gamma} \sqrt{\frac{2 \gamma}{(\gamma-1) R T_{0}}\left(1-\left(\frac{1}{N P R_{\text {crit }}}\right)^{\frac{\gamma-1}{\gamma}}\right)}
\end{aligned}
$$

For the dual-stream nozzle the derived corrections $(\boldsymbol{C F}=$ $\left.\frac{\left.\mathbf{C f g}_{\text {core }}\right|_{\text {FNPR }}}{\left.\mathbf{C f g}_{\text {core }}\right|_{\text {FNPR }=1.0}}\right)$ will capture the impact of the bypass stream tube on the core nozzle flow and components (plug), (Fig 5). It can be seen that CF increased with $\beta$ and FNPR.

These correction factors will be used to scale the value of $\mathrm{C}_{\mathrm{fg}}$ that has been extracted for the BP nozzle. These factors include the impact of the flow interaction between the BP and the core nozzle and the free stream and BP flow. Therefore, the impact of these on the core nozzle flow was considered.

The performance maps provide the modified and improved $\mathrm{C}_{\mathrm{fg}}$ values that capture the effect of various degrees of freedom that are affecting the nozzle performance. Therefore, instead of the typical current one-dimensional maps that illustrate the NPR impact only for a single nozzle configuration[7,8], the multidimensional effect of the flow has been quantified. In the current work, two samples of the used maps are presented, while a detailed description is offered at Al-Akam et al. [11,12]. 


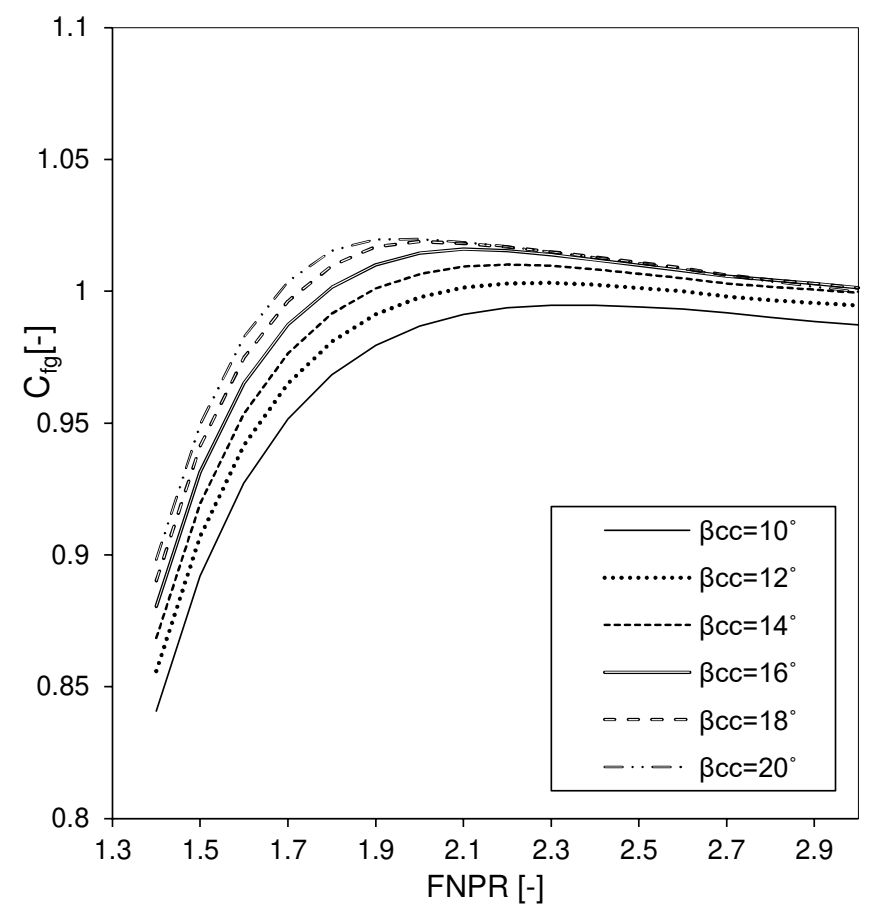

Figure 4. BP nozzle gross thrust coefficient maps as a function of the NPR and $\beta$ for the chosen CR at mid-cruise operational conditions.

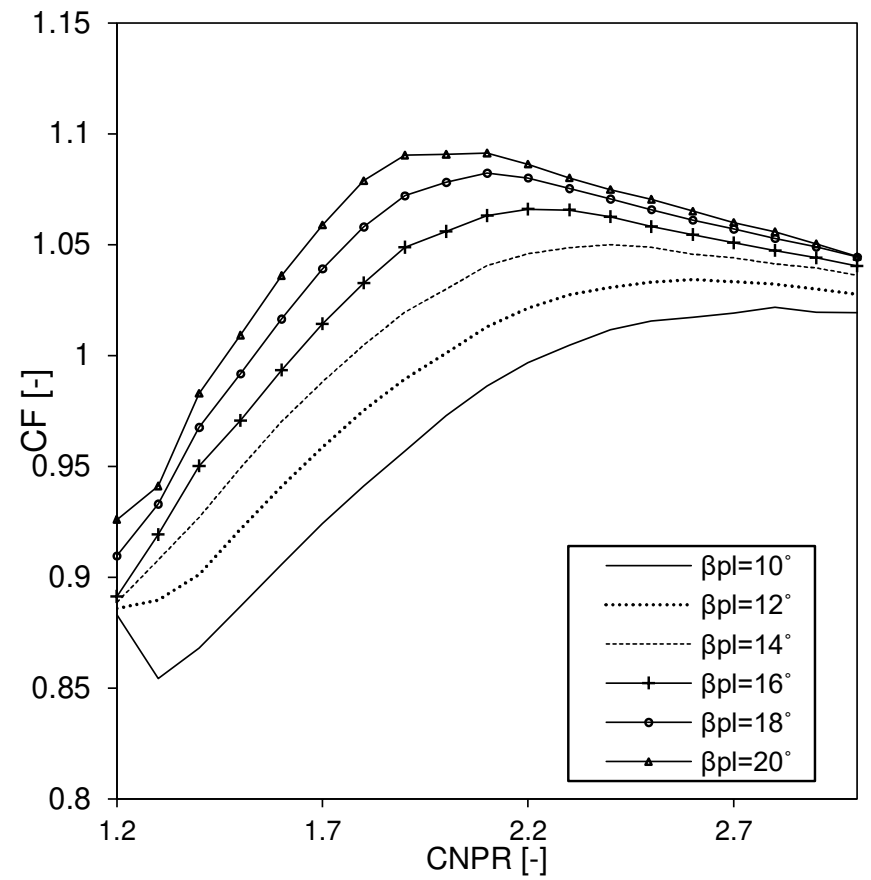

Figure 5. Extracted corrections of the core nozzle gross thrust coefficient, at FNPR $=2.8$ and cCR of 1.5 , of a nozzle running at $\mathrm{M}_{\infty}=0.82$.

\subsection{Extracting the performance metrics}

The nozzle maps, presented in Section 2.3, have to be integrated into an engine performance model. These maps were integrated using response surface methods (RSM). Two response surface methods (RSM) were selected, the cubic spline (CS) and the linear one. These methods were used to extract the performance metric to be used in the calculation method of the engine thrust. Therefore, the thrust calculation now is more sensitive to the impact of the change in the operational and geometrical parameter.

\subsection{Baseline nozzle thrust calculation method}

A simplified thrust calculation can be done by using equation 1 , where $\mathrm{Cv}$ is the velocity coefficient, $\mathrm{Ve}$ is exit velocity and $\left(\left(\boldsymbol{p}_{\boldsymbol{e}}-\boldsymbol{p}_{\infty}\right) \boldsymbol{A}_{\boldsymbol{e}}\right)$, is the pressure thrust term. $\mathrm{Cv}$ is extracted from the nozzle's performance map which is a function NPR and area ratio (AR).

To select the required value of $\mathrm{Cv}, \mathrm{NPR}$ and $\mathrm{AR}$ are required. The value of $A R$ is calculated in the design point performance or defined by the user at off-design operation. The value of NPR is guessed by the solver during the off-design calculations to satisfy mass flow compatibility between the turbine and the nozzle. The value of $\mathrm{C}_{\mathrm{v}}$ is then extracted from the map and utilized in the evaluation of the engine gross thrust, (Equation 6). The following roadmap presents the engine thrust calculation, Fig 6 .

$$
F_{g}=C_{v} m_{e} V_{e}+\left(p_{e}-p_{\infty}\right) A_{e}
$$

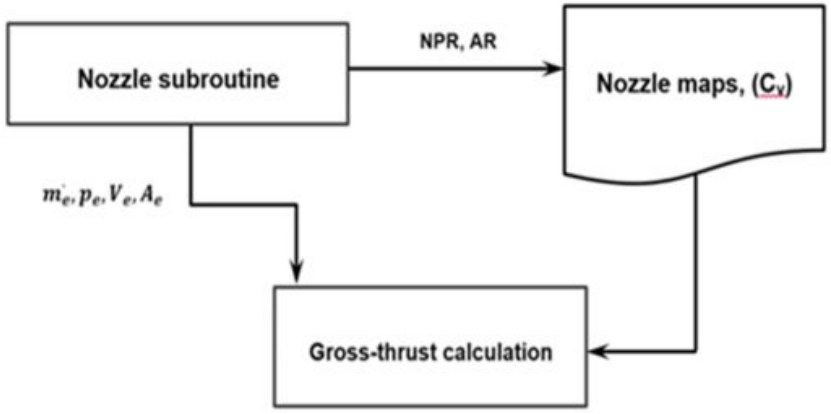

Figure 6. Baseline nozzle thrust calculation roadmap.

\subsection{Improved nozzle thrust calculation method}

In the improved performance model, the nozzle maps depend on additional geometrical and operational parameters, which are FNPR, CNPR, core cowl angle $\left(\beta_{\mathrm{cc}}\right)$, plug-half angle $\left(\beta_{\mathrm{pl}}\right)$ and CR. Two types of nozzle maps have been used in the improved thrust calculation. These are the thrust coefficient maps for the BP nozzle, (Fig. 4) and correction factor maps for the core nozzle, (Fig. 5).

For the bypass nozzle, a three-dimensional RSM based on the nozzle maps was used to enable a proper selection process for the nozzle performance characteristic. This method takes FNPR as input from the fan output parameter, as it was calculated from in individual fan subroutine. Core-cowl angle $\left(\beta_{\mathrm{cc}}\right)$ (from $10^{\circ}-20^{\circ}$ ) is an input to the model. CR is calculated 
internally in the code based on previous estimation of the nozzle exit area, mass flow rate and total pressure and temperature, (Fig 7). The nozzle inlet area is calculated by using a one-dimensional mass flow rate equation as a function of Mach number and mass flow rate. In the current work, the inlet Mach number of the nozzle was varied in a range of $0.35-0.45$ [13]. Therefore, to parametrise $\mathrm{CR}$ for both nozzles, $\mathrm{M}_{\text {in }}$ value is varied.

In the case of the core nozzle, the same procedure of the bypass nozzle was followed, the only exception is to include the impact of the FNPR. Therefore, FNPR as an additional parameter was added to the selection process, but the same RSM was implemented.

The parameters that are required to be imported to the selection function to extract the nozzle coefficient are FNPR, CNPR, $\beta_{\mathrm{cc}}, \beta_{\mathrm{pl}}, \mathrm{CR}$, cCR (core nozzle contraction ratio), Fig 8. The cubic spline response surface method was used to estimate the response as a function of the FNPR and CNPR. Nevertheless, interpolating the data as a function of the $\mathrm{CR}$ and $\beta$ was kept linear as it was found sufficient for this case.

A new thrust definition has been used $\left(\mathrm{F}_{g}\right)$ for the $\mathrm{BP}$ and the core-nozzle, (Equation 7). The derived value of the gross thrust coefficient $\left(\mathrm{C}_{\mathrm{fg}}\right)$ includes the impact of the geometry variation on the pressure-thrust term, (Equation 1). It can be seen that this definition includes the momentum flux term only $\left(\mathrm{m}_{\mathrm{i} \text { nozzle }} \mathrm{V}_{\mathrm{s}}\right)$, as compared with the thrust equation 6 , as the thrust definition that has been used in the calculation of the $\mathrm{C}_{\mathrm{fg}}$ considered the impact of the pressure-thrust term during the CFD calculations,(Section 2.3). The roadmap of the modified thrust calculations is presented in Fig 7. The term brick data" is an input data to the nozzle component. The methodology was applied for both nozzles (bypass and core nozzle). Since the core nozzle is affected by the presence of the bypass flow, a correction factor map was used instead of the $\mathrm{C}_{\mathrm{fg}}$ maps. So that the coefficient of the thrust is scaled by the value of $\mathrm{CF}$, Equation (8).

$$
\begin{aligned}
& F_{g}=C_{f g} m_{i \text { nozzle }} V_{s} \\
& F_{g}=C F C_{f g} m_{\text {i nozzle }} V_{s}
\end{aligned}
$$

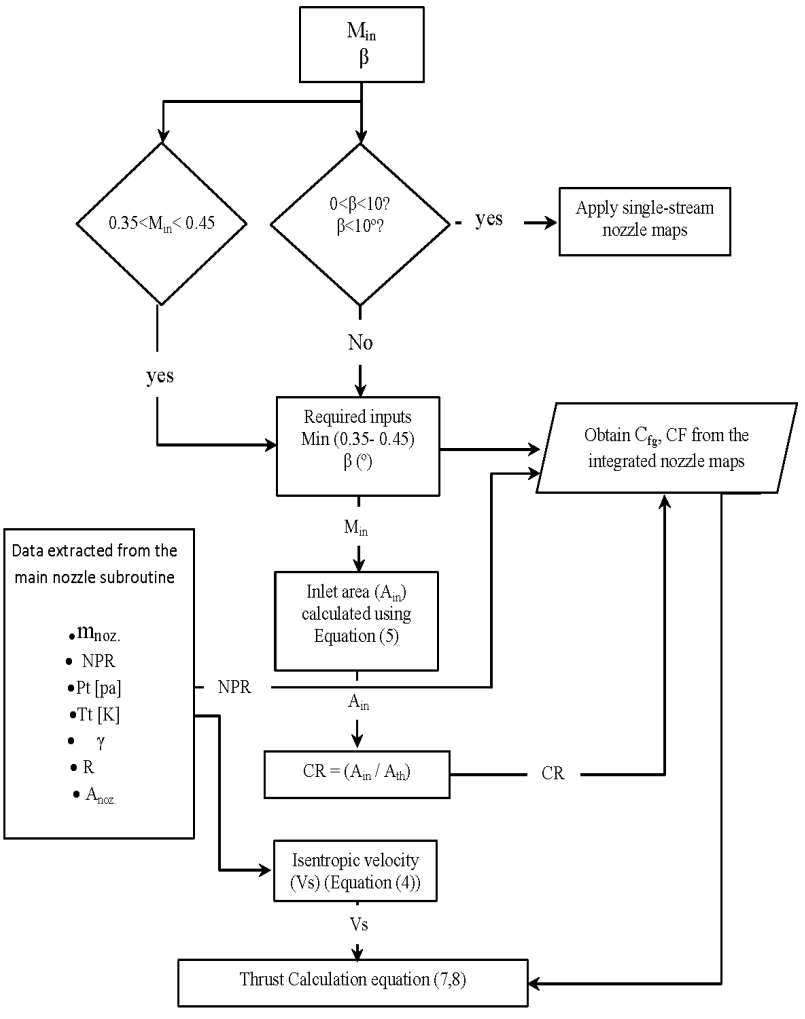

Figure 7. Roadmap of the improved thrust calculation.

\subsection{Test cases}

\subsubsection{Impact of core-cowl $\left(\beta_{\mathrm{cc}}\right)$ and plug angle $\left(\boldsymbol{\beta}_{\mathrm{pl}}\right)$}

The $\beta_{\mathrm{cc}}$ was changed across a range from $10^{\circ}$ to $20^{\circ}$ with a step of $2.0^{\circ}$; two $\beta_{\mathrm{pl}}$ levels were chosen and investigated for each $\beta_{c c}$. Two different engine cases were considered, which were inspired by Trent 1000 and CF6-80E1, denoted in this work by E1 and E2, respectively. Furthermore, three cases, for each engine class, to check the validity of the new model, were considered.

\subsubsection{Impact of Contraction ratio (CR)}

The CR was changed by varying the inlet Mach number $\left(\mathrm{M}_{\text {in }}\right)$ (Fan and turbine exit Mach number) of the nozzle. Three different values were selected to capture the effect of the CR on the engine gross thrust; they are $0.36,0.4$ and 0.45 , the corresponding value $\mathrm{CR}$ and $\mathrm{cCR}$ are presented in Table 3 . Inlet Mach number $\left(\mathrm{M}_{\mathrm{in}}\right)$ of 0.45 was chosen to be the baseline DP calculations of the engine.

Table 3. Fan and core duct inlet Mach number $\left(\mathrm{M}_{\text {in }}\right)$ and corresponding contraction ratio (CR).

\begin{tabular}{crcll}
\hline Engine Class & Case\# & $\mathbf{M}_{\text {in }}[-]$ & CR [-] & cCR [-] \\
\hline \multirow{2}{*}{ E1 } & 1 & 0.36 & 1.73 & 1.72 \\
& 2 & 0.40 & 1.60 & 1.57 \\
& 3 & 0.45 & 1.45 & 1.44 \\
\hline \multirow{2}{*}{ E2 } & 1 & 0.36 & 1.72 & 1.74 \\
& 2 & 0.40 & 1.60 & 1.60 \\
& 3 & 0.45 & 1.45 & 1.46 \\
\hline
\end{tabular}




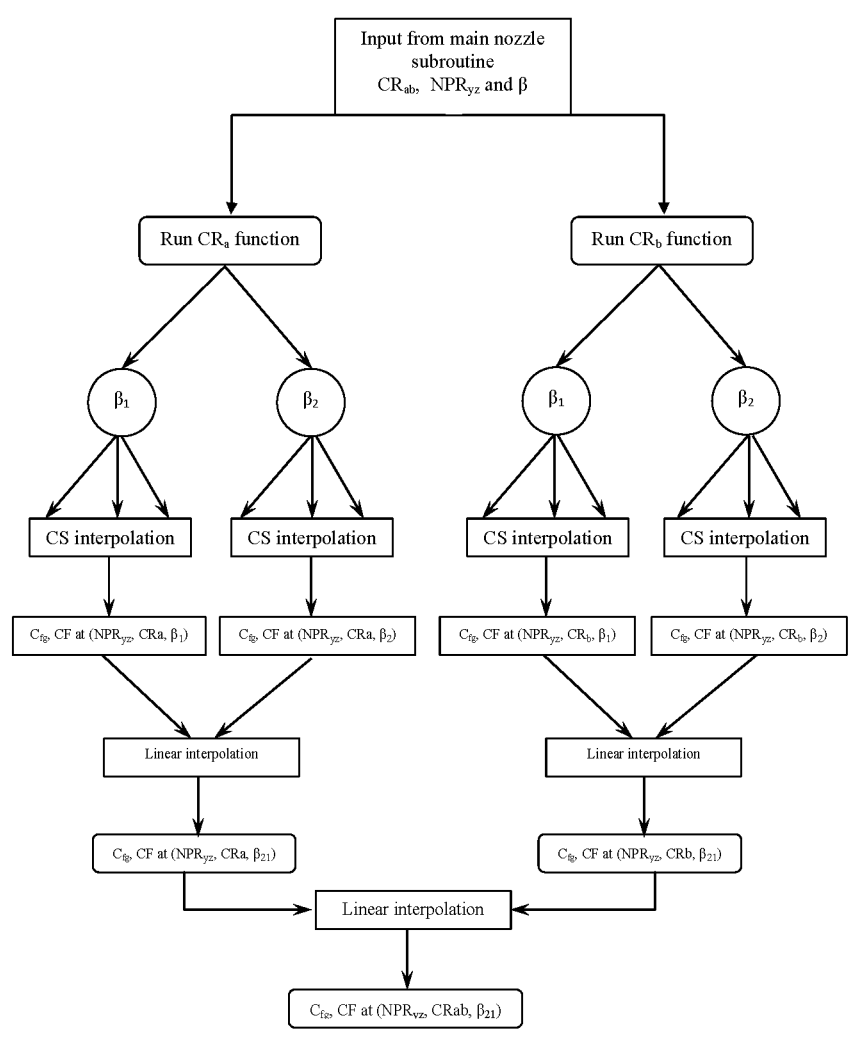

Figure 8. Selection procedure of the nozzle performance metric in the new maps, using two different RSM.

\subsubsection{Impact of the operating conditions}

Fan maps were plotted for the conventional and the modified engine performance model as a function of fan pressure ratios and the corrected mass flow rate. The contraction ratio (CR) was kept constant at its design point values at associated $\mathrm{M}_{\text {in }}$ (fan exit Mach number) of 0.45 . $\beta$ (core-cowl or plug one), is a design parameter of the nozzle, it can be handled easily in the code during the calculations, without affecting the other geometrical features of the engine.

\section{RESULTS AND DISCUSSION}

\subsection{Engine thrust sensitivity to the parameterization of the nozzles}

The results of the thrust were presented in terms of the ratio of $\frac{F g}{F g_{\text {basline }}}$. The baseline thrust of the E1 class engine is $64 \mathrm{kN}$ and for $\mathrm{E} 2$ engine class is $52 \mathrm{kN}$. The geometrical features of the baseline engine regarding the $\beta_{\mathrm{cc}}, \beta_{\mathrm{pl}}, \mathrm{CR}$ and $\mathrm{cCR}$ are $14^{\circ}, 18^{\circ}$, $1.45,1.44$ respectively. The results showed that the implementation of the new nozzle performance maps produced thrust levels higher than the conventional one for all the range of geometrical parameters investigated in this work. For the conventional engine design (Class E1) the $\beta_{\mathrm{cc}}$ and $\beta_{\mathrm{pl}}$ have the values of $14^{\circ}$ and $20^{\circ}$. If a new geometrical feature were selected for the exhaust system, the result showed that the thrust levels can be increased by $0.05 \%$ if the engine was designed at $\beta_{\mathrm{cc}}=$ $20^{\circ}$ and $\beta_{\mathrm{pl}}=20^{\circ}$. For both cased the value of the CR were kept fixed at 1.6 for CR and 1.57 for cCR, (Fig 9) (solid circles). As a result of the increase in the thrust levels due to the inclusion of the impact of the geometrical features. Moreover, by increasing the CR of the BP nozzle and the core nozzle to 1.73 and 1.72 , respectively the increase in the thrust for the selected configuration will be $0.2 \%$ (Fig 9) (dotted circles).

The comparison between the two engine classes sowed that E2 engine class performance data showed a more noticeable combined impact of the aerodynamic and geometric parameters variation on this engine class. (Fig 9). This can be seen from the thrust levels with exhaust system feature of $\beta_{\mathrm{pl}}=10^{\circ}$ and 1.73 and 1.72 for $\mathrm{CR}$ and $\mathrm{CCR}$, respectively, for $\mathrm{E} 2$ as there are a noticeable interaction with the engine that has $\mathrm{CR}$ and $\mathrm{cCR}$ of 1.6 and 1.57. This not the case for E1 class engine.

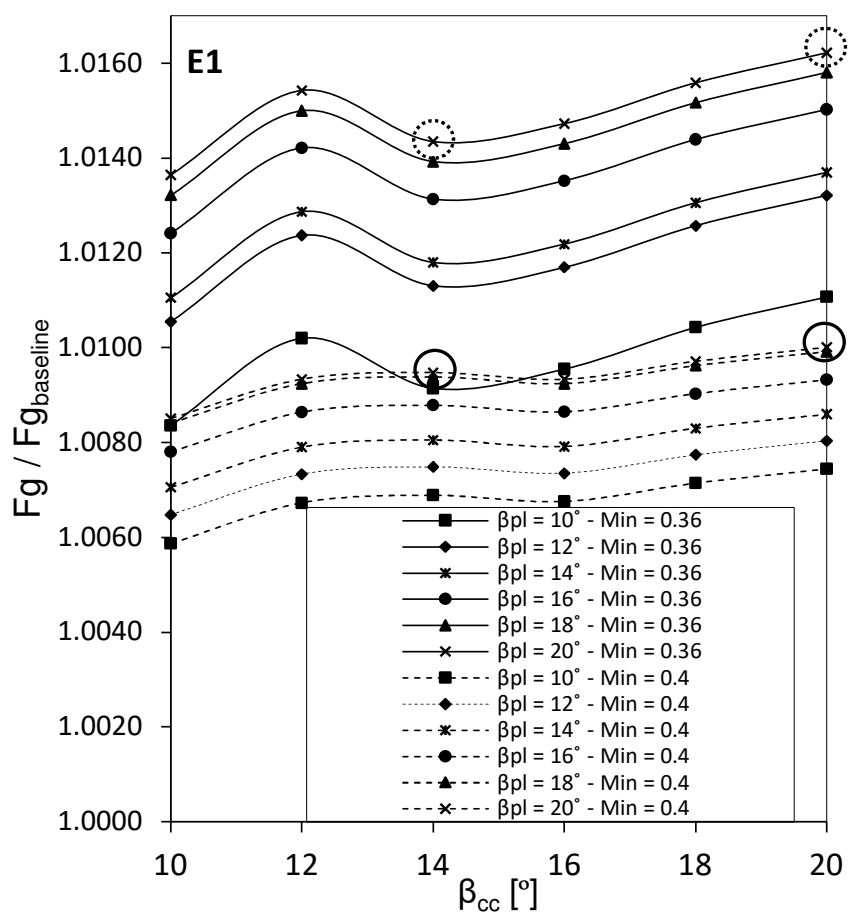




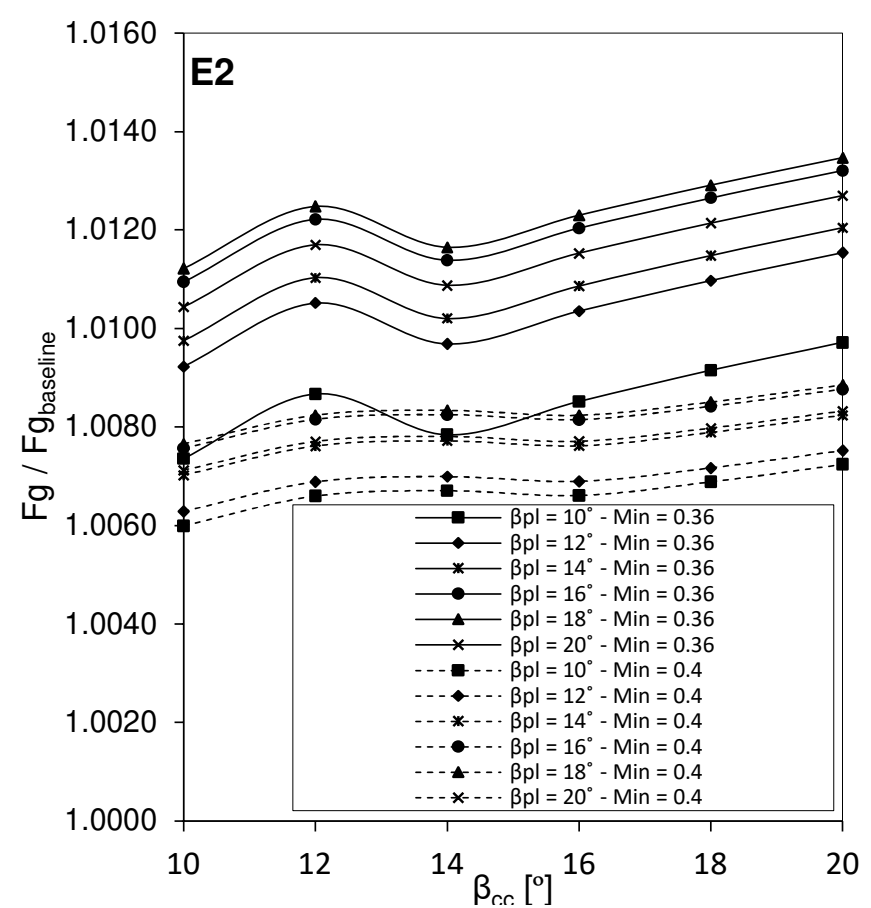

Figure 9. Sensitivity of the gross thrust to the variation of the engine power settings and the nozzle contraction ratio (CR) and core cowl angle $\left(\beta_{\mathrm{cc}}\right)$ and plug angle $\left(\beta_{\mathrm{pl}}\right)$; running at Alt. $=11000 \mathrm{~m}$ for two different engine class.

To capture the impact of the new calculations procedure on the engine fuel consumption, the nozzle thrust was kept constant, and the SFC of the engine was evaluated. These results are presented for different engine classes and geometrical configuration as presented in Fig 10 - Fig 11. The results were normalised to the value of SFC evaluated from baseline performance model ( $\left.\mathrm{SFC}_{\text {baseline}}\right)$. It can be seen that the engine SFC is lower than the baseline data after implementing the new thrust calculations method. This is attributed to the increase of the core-cowl and the plug angles. This geometry causes an increase in the levels of $\mathrm{C}_{\mathrm{fg}}$ and $\mathrm{CF}$ because of the increase in the pressure force over the core-cowl and the plug, which acts as an additional thrust.

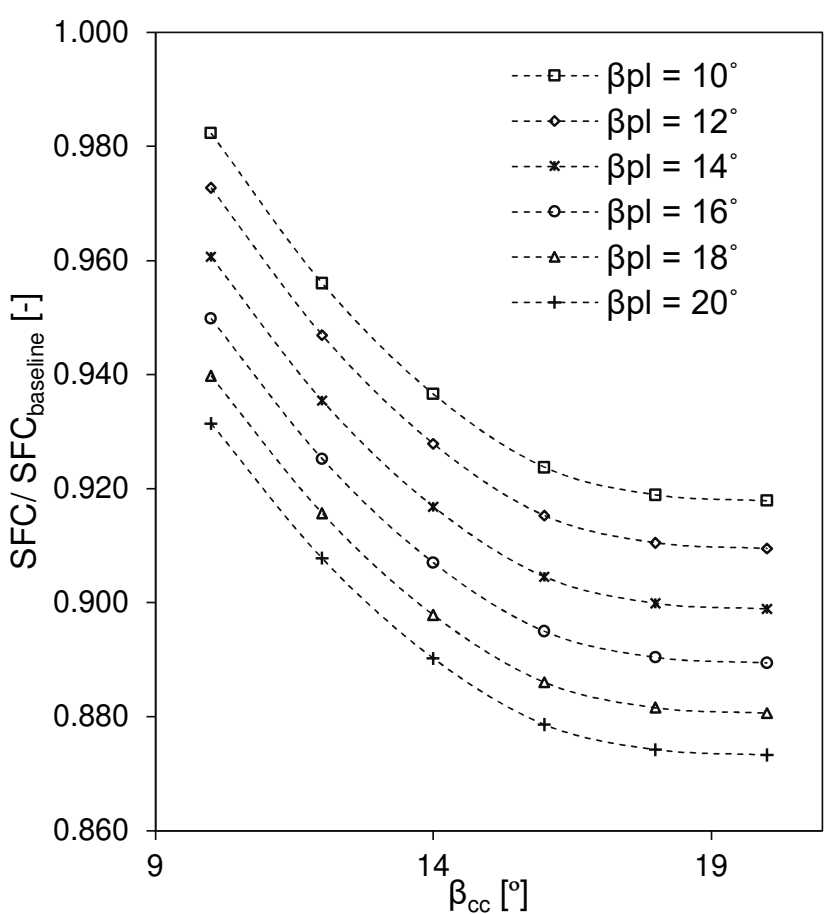

(a)

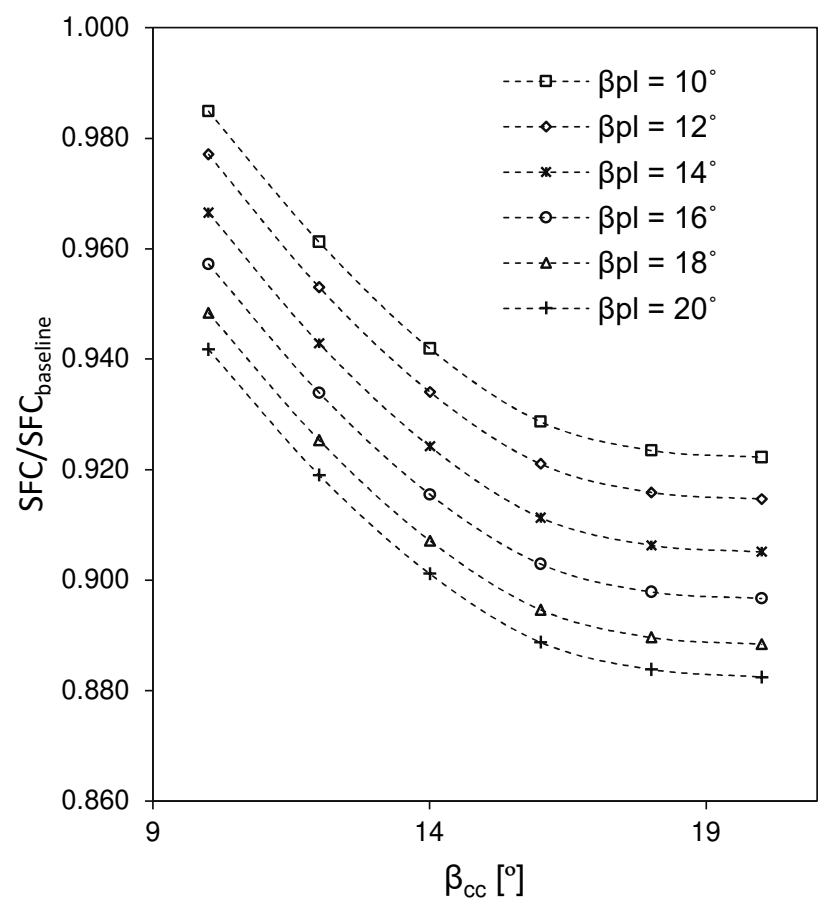

(b)

Figure 10. SFC comparison between the conventional and the improved thrust calculations as a function of the core-cowl and plug angles, for E1 engine class performance data; (a) BP engine conditions, with thrust rating of $64 \mathrm{kN}$ (b) OD run; at Alt. $=11000 \mathrm{~m}$ and $\mathrm{M}_{\infty}=0.85$. 


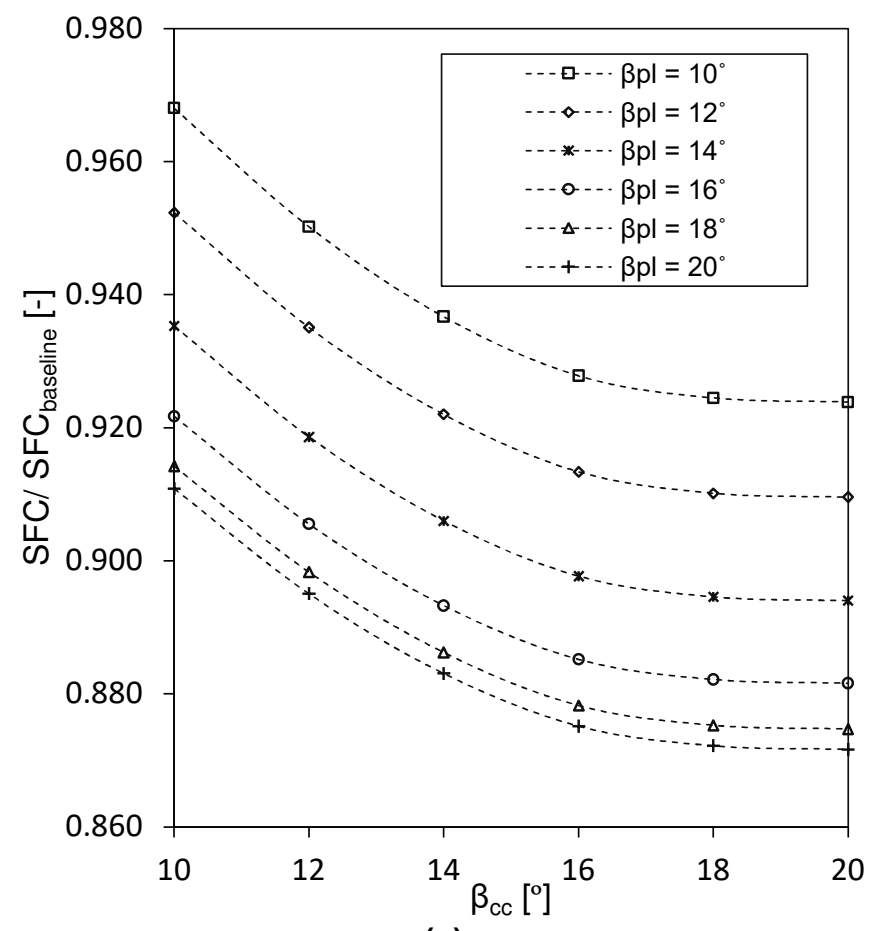

(a)

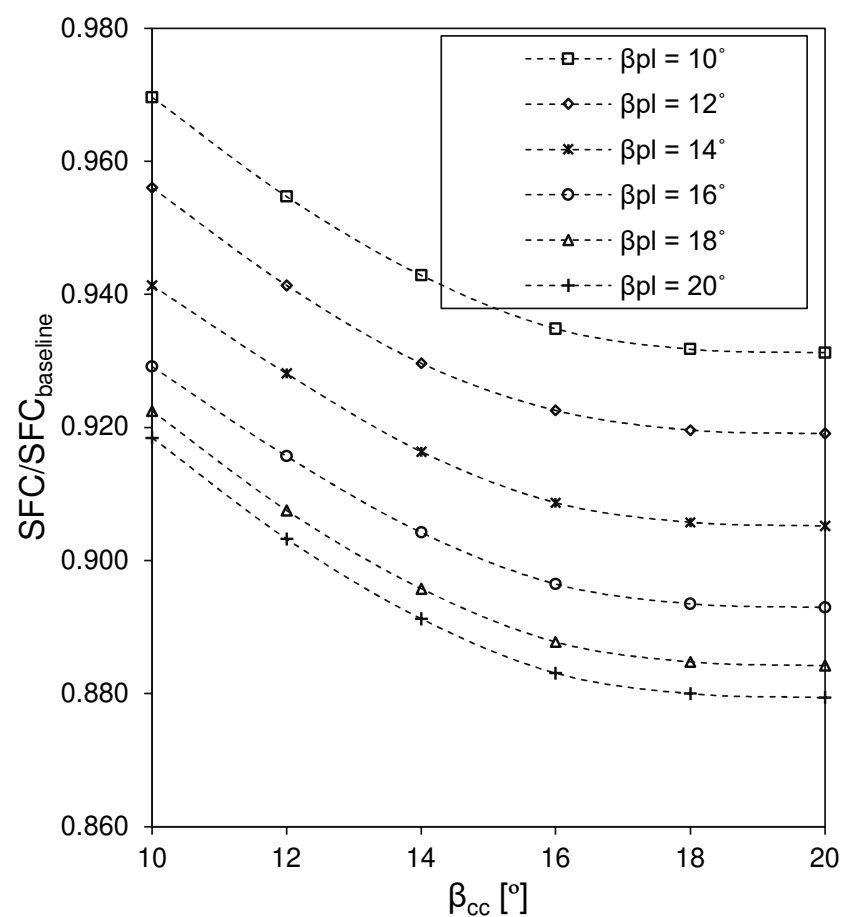

(b)

Figure 11. SFC comparison between the conventional and the improved thrust calculations as a function of the core-cowl and plug angles, for E2 engine class performance data; (a) BP engine run, with thrust rating of $52 \mathrm{kN}$ (b) OD engine run; running at Alt. $=11000 \mathrm{~m}$ and $\mathrm{M}_{\infty}=0.82$.

\subsection{Engine sizing}

As can be noted from the previous section, the core-cowl and the plug angle have a significant impact on the thrust levels. The results of the DP calculation for both conventional and improved method for engine class E2 are presented in Table 4. The angle of the core-cowl $\left(\beta_{\mathrm{cc}}\right)$ was chosen to be $14^{\circ}$ and $18^{\circ}$ for the plug nozzle.

Due to the increase in the thrust as a result of the additional thrust extracted from the exhaust system components, the engine size might be changed. Because this increase in the thrust will be translated to the reduction in the mass flow rate of the engine and consequently the area of the nozzle, Table 4 . This reduction in the mass flow is attributed to the reduction in throttle setting of the engine for the requested thrust.

Table 4. Test cases result of E2 engine.

\begin{tabular}{llc}
\hline Engine parameters & Current DP run & New DP run \\
\hline $\mathrm{m}_{\text {in }}[\mathrm{kg} / \mathrm{s}]$ & 576 & 516.1 \\
FNPR & 2.45 & 2.45 \\
$\mathrm{CNPR}$ & 1.91 & 1.91 \\
$\mathrm{Abp}\left[\mathrm{m}^{2}\right]$ & 3.7 & 3.31 \\
Acore $\left[\mathrm{m}^{2}\right]$ & 0.876 & 0.785 \\
\hline
\end{tabular}

\subsection{Impact on the fan operating point (OP)}

The impact of using the enhanced nozzle maps on the operating point (OP) of the fan is presented in Fig. 12. The presented results are for E1 engine class in two cases: the conventional and the extreme levels of $\beta_{\mathrm{cc}}$ and $\beta_{\mathrm{pl}}$ of $\left(20^{\circ}\right)$. Based on the fan map, Fig 12, the operating point moves down with lower pressure ratio and with an insignificant change in the mass flow rate as compared with the conventional case (current OP), Fig 12.

The impact of the variation of the core-cowl and plug angle on the mass flow rate, the pressure ratio of the BP nozzles is presented in Fig 13 - Fig 14. It can be noted that there is a reduction in both the mass flow rate and the pressure ratio with an increase in core cowl and plug angle. This can be attributed to a reduction in the mass flow rate and the pressure ratio of the fan due to the inclusion of the additional pressure thrust in the gross thrust coefficient calculation. 


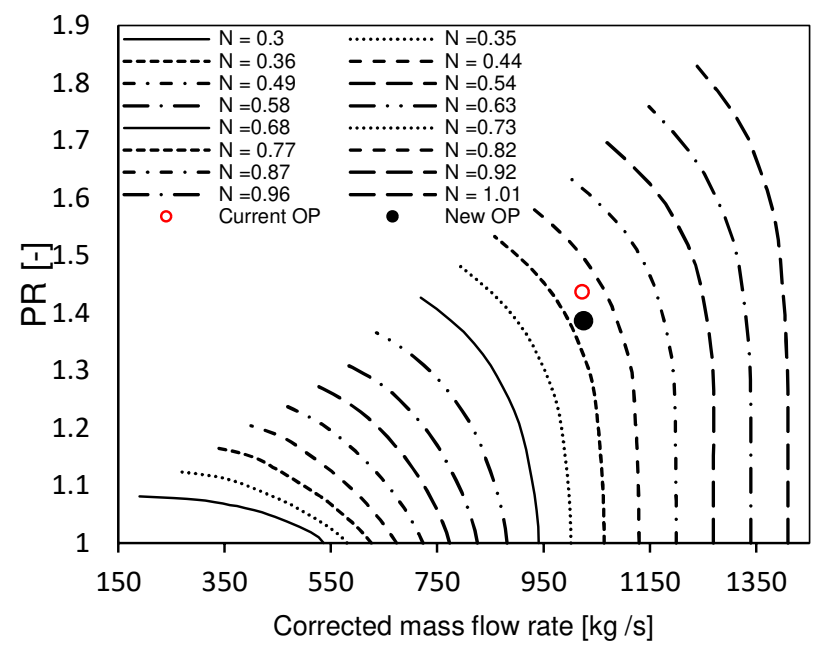

Figure 12. Fan maps of $\mathrm{E} 1$ engine class running at thrust rating of $45 \mathrm{kN}$; showing the location of the current and the new operating point of the fan.

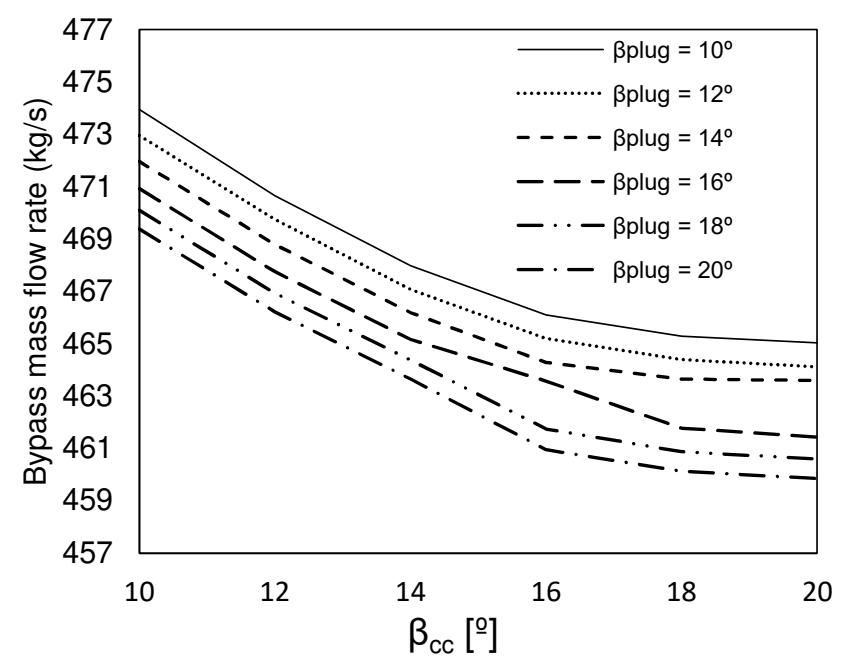

Figure 13. Bypass mass flow rate as a function of the corecowl and plug angle of E1 class engine running at $45 \mathrm{kN}$ thrust rating at cruise conditions, Alt $=11000 \mathrm{~m}$.

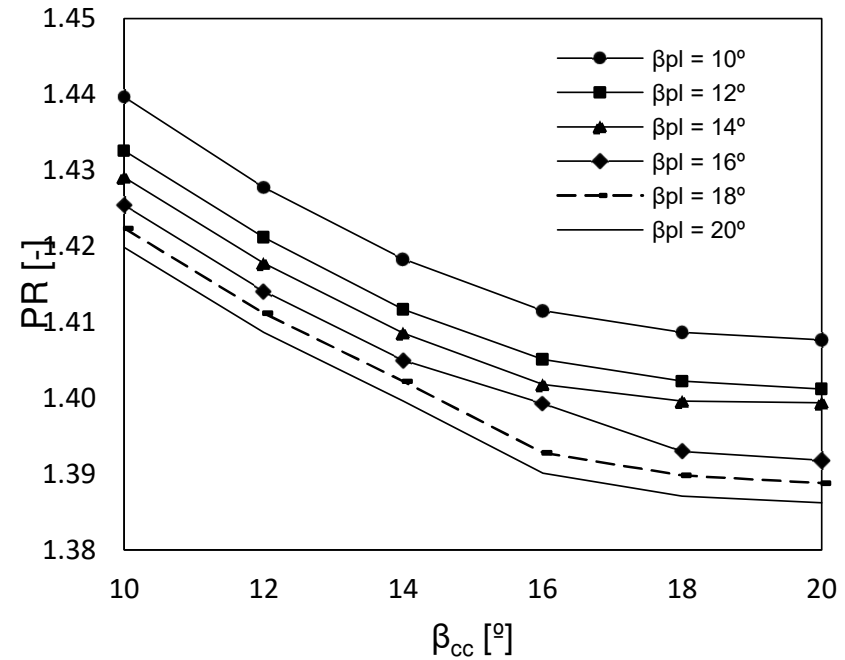

Figure 14. Fan pressure ratio as a function of the core-cowl and plug angle of E1 class engine running at $45 \mathrm{kN}$ thrust rating at cruise conditions, alt $=11000 \mathrm{~m}$.

\section{CONCLUSION}

This work integrates a new set of performance metrics maps of the nozzle into an engine performance model. These maps take into consideration the combined impact of the geometric features and the aerodynamic parameters variation on the performance of the engine.

The results showed that the geometric characteristics of the exhaust system (core cowl and the plug angles) should be considered in the thrust calculation. In the cases presented in this manuscript, there is an improvement in the engine SFC estimation and the thrust rating when these parameters are included in the performance simulation. The maximum increase in the gross thrust value is estimated to be $0.2 \%$ for specific engine class. This difference can affect the engine's design. The new thrust calculation method produces more consistent performance results by considering the geometrical feature of the exhaust-system.

\section{REFERENCES}

[1] MacMillan, W. L., 1974, "Development of a ModularType Computer Program for the Calculation of Gas Turbine off-Design Performance," PhD Thesis, Cranfield University,UK.

[2] Kurzke, J., 2018, "Gas Turb 13 Manual."

[3] Mund, F. C., Doulgeris, G., and Pilidis, P., 2007, "Enhanced Gas Turbine Performance Simulation Using CFD Modules in a 2D Representation of the LowPressure System for a High-Bypass Turbofan," J. Eng. Gas Turbines Power, 129(3), pp. 761-768.

[4] Sibilli, T., 2012, "Modelling the Aerodynamics of Propulsive System Integration at Cruise and High-Lift Conditions," Ph.D CRANFIELD UNIVERSITY. 
"Aero - Engine Installation Modelling and the Impact on Overall Flight Performance,” Adv. Aero Concepts, Des. Oper.

[6] Laskaridis, P., Pilidis, P., and Kotsiopoulos, P., 2005, "An Integrated Engine--Aircraft Performance Platform for Assessing New Technologies in Aeronautics," Isabe 2005, pp. 1-13.

[7] Thornock, R. L.; Brown, E. F., 1972, “An Experimental Study of Compressible Flow through ConvergentConical Nozzles, Including a Comparison with Theoretical Results,” J. Basic Eng., 94, pp. 926-930.

[8] Harrington, D. E., 1970, Performance of Convergent and Plug Nozzles at Mach Numbers from 0 to 1.97.

[9] Al-Akam, A., Nikolaidis, T., and MacManus, D. G., 2019, "Computational Fluid Dynamics-Based Approach for Low-Order Models of Propelling Nozzle Performance," Proc. Inst. Mech. Eng. Part G J. Aerosp. Eng., 233(13), pp. 4879-4894.

[10] ANSYS Inc., 2013, “ANSYS Fluent Theory Guide 14.0, November,2013," (November).

[11] Al-akam, A., Nikolaidis, T., and Macmanus, D. G., 2019, "Computational Fluid Dynamics-Based Approach for Low-Order Models of Propelling Nozzle Performance," $\mathbf{0}(0)$, pp. 1-16.

[12] Al-akam, A., Nikolaidis, T., Macmanus, D. G., Goulos, I., and Centre, P. E., 2019, "Numerical Model for Predicting the Aerodynamic Characteristics of Propelling Nozzles," pp. 1-24.

[13] Walsh, P. P., and Fletcher, P., 2004, Gas Turbine Performance, Blackwell Science Ltd. 
2021-09-16

\title{
The use of enhanced nozzle maps for gas-turbine performance modelling
}

\author{
Al-Akam, Aws A.
}

American Society of Mechanical Engineers

\begin{abstract}
Al-Akam AA, Nikolaidis T, MacManus DG, Pellegrini A. (2021) The use of enhanced nozzle maps for gas-turbine performance modelling. In: ASME Turbo Expo 2021: Turbomachinery Technical Conference and Exposition, 7-11 June 2021, Virtual Event https://doi.org/10.1115/GT2021-60029

Downloaded from Cranfield Library Services E-Repository
\end{abstract}

